\title{
Development of ethanol tolerance in relation to the alcohol dehydrogenase locus in Drosophila melanogaster. II. The influence of phenotypic adaptation and maternal effect on survival on alcohol supplemented media
}

\author{
Willem J. M. Kerver and \\ Gerrit Rotman
}

Department of Genetics, University of Groningen, Kerklaan 30, 9751 NN Haren (Gn.), The Netherlands.

The role of phenotypic adaptation and maternal effects in the survival of Drosophila melanogaster on media supplemented with alcohol was investigated. Egg-to-adult survival depends on the age at which the eggs are transferred from regular to ethanol-containing food. Eggs transferred at an age of 8 hours or less, produce significantly more adults than eggs transferred after 14 hours. This phenomenon is not observed when eggs are exposed only temporarily to ethanol at different ages. Phenotypic adaptation was also observed on food supplemented with propanol, butanol and hexanol for strains not selected for ethanol tolerance. Maternal effects had a great influence on egg-to-adult survival on ethanol-supplemented food. Eggs homozygous for the $A d h^{n 1}$ allele showed a significantly better survival on 4 per cent ethanol food when laid by ADH-positive mothers, than laid by ADH-negative mothers. This maternal effect was probably caused by maternal ADH and not by maternal mRNA. Phenotypic adaptation and maternal effect are both important in the survival of $D$. melanogaster on food containing alcohol, especially in the case of selection during pre-adult life stages.

\section{INTRODUCTION}

The alcohol dehydrogenase (Adh) locus of Drosophila melanogaster is one of the few allozyme loci for which selection has been shown. It is universally polymorphic for two common alleles, $F$ and $S$, and there are genotypic differences in the tolerance to ethanol and in in vitro $\mathrm{ADH}$ activity. Clines in allele frequencies have also been observed. The mechanisms behind the maintenance of this world wide polymorphism are not yet clear (Van Delden, 1982). Survival on ethanol supplemented media is, however, not totally dependent on ADH activity as exposure of eggs to ethanol induced an increase in ethanol tolerance in larvae (Bijlsma-Meeles, 1979). Egg-to-adult survival depends on the age at which the eggs were transferred to ethanol-containing food; larvae from eggs transferred early showed a much higher viability than larvae from eggs transferred later. This phenotypic effect was associated with an increase in ADH activity in ethanol-treated eggs as compared with nontreated eggs.
A similar increase in activity after exposure to ethanol has been found for larvae (Gibson, 1970) and embryonic cells (Horikawa, King and Fox, 1967). However, results of Wright and Shaw (1970) and Leibenguth, Rammo and Dubiczky (1979) suggest that the Adh locus is not expressed until the 20th hour of egg development; until then embryos show only the maternal form of the enzyme. The relation between $\mathrm{ADH}$ activity and survival on alcohol-containing media is complex (Kerver and Van Delden, 1985).

This paper investigates the role of phenotypic adaptation and maternal effects for survival on alcohol supplemented media. We explore the effects of age of exposure of eggs to ethanol on increased tolerance in order to elucidate the mechanism of tolerance to alcohols. Strains homozygous for the $A d h^{S}$ and the $A d h^{F}$ allele were kept for many generations on food supplemented with ethanol, as ethanol is the most abundant alcohol in the natural environment of $D$. melanogaster (Castelli, 1954; Hulme, 1970, 1971; Briscoe, Robertson and Malpica, 1975; McKenzie 
and McKechnie, 1979). We found also that the maternal genotype can influence the survival of $D$. melanogaster on ethanol-containing food.

\section{MATERIALS AND METHODS}

\section{Strains}

Two ADH positive strains of Drosophila melanogaster, one homozygous for $A d h^{F}$ and one for $A d h^{S}$ were used. Each strain was composed by intercrossing 8 homozygous Groningen-B lines of the appropriate genotype (for details see Van Delden, Boerema and Kamping, 1978). Both strains were kept continuously on regular food for about 130 generations and, for selection purposes, on food containing ethanol for about 100 generations. The $A d h^{F}$ and $A d h^{S}$ strains kept on regular food will be referred to as $F N$ and $S N$ respectively, while the strains kept on ethanol supplemented food will be called $F E$ and $S E$.

Two ADH-negative strains were used. These were produced by introducing the $A d h^{n 1}$ allele (Grell, Jacobson and Murphy, 1968) into the backgrounds of the Groningen-B lines (Van Delden and Kamping, 1981).
Both strains, one with the $A d h^{F}$ background (referred to as $O_{F}$ ) and the other with the $A d h^{S}$ background $\left(O_{S}\right)$ had been kept on regular food for 90 generations. Heterozygotes from crosses between $F N$ and $O_{F}$ will be indicated as $F O_{F}$ (and their alternative as $S O_{S}$ ), those from the reciprocal crosses as $O_{F} F$ (respectively $O_{S} S$ ) (see also fig. 2).

\section{Food and culture conditions}

Regular food contained $18 \mathrm{~g}$ agar, $54 \mathrm{~g}$ sucrose, $32 \mathrm{~g}$ dried dead yeast and $13 \mathrm{ml}$ of a solution of $10 \mathrm{~g}$ nipagin in $100 \mathrm{ml}$ ethanol (96 per cent) in 11 water. Alcohol-containing food was made by adding the appropriate volume of alcohol to normal medium with vigorous stirring, after the medium had been cooled to $50^{\circ} \mathrm{C}$. For the $E$ strains the ethanol concentration was raised from an initial 12 per cent by volume to 18 per cent in three steps.

Each of the six strains was maintained in 20 bottles $(125 \mathrm{ml})$ containing $30 \mathrm{ml}$ of food as described by Kerver and Van Delden, 1985. All experiments were performed at $25^{\circ} \mathrm{C}$ and $50-70$ per cent R.H.

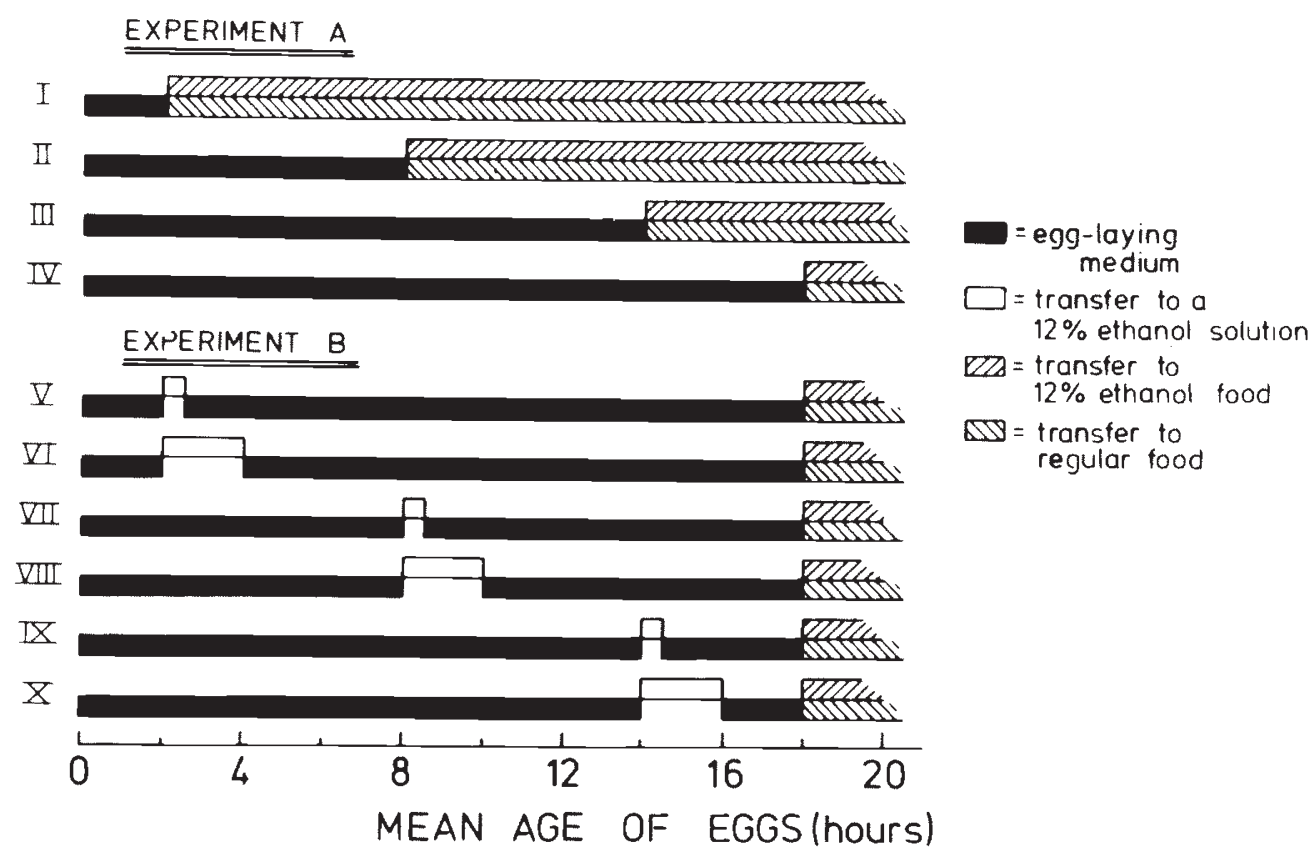

Figure 1 The procedure followed in the experiment concerning the induction of tolerance to ethanol during the egg stage. All eggs were laid on regular food during a period of 4 hours (mean age of the eggs after that time was taken as 2 hours). In experiment A the eggs were kept on the egg-laying medium until they were transferred to the test media, either regular food or food containing 12 per cent ethanol. In experiment B all eggs were kept on the egg-laying medium for the first 18 hours, except for the induction period in a 12 per cent ethanol solution, and then transferred to the test media. The Roman numerals refer to the different treatments of the eggs; they are identical to the numerals in table 2 . For further details see text. 


\section{Induction of tolerance to ethanol during the egg-stage}

Induction of tolerance to ethanol during the eggstage was measured by determining egg-to-adult survival in glass vials containing $9 \mathrm{ml}$ of either regular food or ethanol food (12 per cent $v / v)$. To stimulate egg production flies were fed with additional live yeast during 3 days before transferring them to the egg-laying bottles. These bottles were provided with a glass plate $(2 \times 10 \mathrm{~cm})$ supplied with a thin layer of regular food and a drop of live yeast.

One half hour after transferring the flies to the egg-laying bottles the glass plates were replaced and the flies were allowed to lay eggs for 4 hours after which they were discarded. The mean age of the eggs after that time was taken as 2 hours. The procedure followed thereafter is outlined in fig. 1 and consisted of two experiments.

In experiment $A$ the eggs were transferred from regular food to vials containing either regular food or ethanol food at different ages $(2,8,14$ or 18 hours respectively) and egg-to-adult survival was determined. In experiment $\mathrm{B}$ a pulse induction was given to eggs at a mean age of 2,8 or 14 hours by transferring them to an aqueous solution of ethanol $(12$ per cent $\mathrm{v} / \mathrm{v})$ in a closed petri dish. In pilot experiments was found that the effects of such exposure were comparable to exposure to ethanolcontaining food. The length of the induction period was either one half hour or 2 hours; the eggs were then replaced on egg laying medium until a mean age of 18 hours. They were then transferred to the vials with regular or ethanol food. For all different treatments 5 replicates of 50 eggs were transferred both to regular and to ethanol food using the egg collecting procedure of Kerver and Van Delden (1985). The number of emerging males and females was determined every day.

In none of the experiments was a significant difference in survival between the sexes observed; therefore males and females were combined and the statistics were performed on the total number of flies.

\section{The influence of the maternal effect on egg-to-adult survival}

To investigate the influence of maternal genotype on egg-to-adult survival the crossing scheme from fig. 2 was carried out.

The crosses of the $P$ generation were performed in $125 \mathrm{ml}$ bottles containing $30 \mathrm{ml}$ of regular food. For the crosses of the F1 generation the parents were fed with additional live yeast for 3 days before transferring them to egg-laying bottles. F2 eggs ( 2 hours old) were collected as described by Kerver and Van Delden (1985). For each cross 10 replicates of 50 eggs were transferred to vials containing $9 \mathrm{ml}$ of either regular food or food supplemented with ethanol ( 4 per cent or 6 per cent $v / v$ ). The total number of emerging flies was determined and all flies were frozen at $-25^{\circ} \mathrm{C}$. $A d h$ genotypes were ascertained by means of a colouring reaction. For this purpose the frozen flies were homogenised individually in a drop of $0.041 \mathrm{M}$ veronal- $\mathrm{HCl}$ $0.001 \mathrm{M}$ EDTA buffer of $p \mathrm{H} \mathrm{8.4}$. Then a drop of staining solution, composed of $10 \mathrm{ml}$ homogenisation buffer with a final concentration of $6 \mathrm{mM} \mathrm{NAD}^{+}, 2.5 \mathrm{mM}$ isopropanol, $7.5 \mathrm{mM}$ MTT and $5 \mathrm{mM}$ PMS was added. In the presence of active $\mathrm{ADH}$ this mixture will become blue because of the reduction of MTT, while it stays yellow in the case an $\mathrm{ADH}$ negative fly is homogenised.

In a separate control experiment the egg-toadult survival of the $F N, S N, O_{F}$ and $O_{S}$ strains was determined on regular food and on 4 per cent ethanol food. Reciprocal crosses between $F N$ and $O_{F}$ and between $S N$ and $O_{S}$ were also performed and the viability of heterozygous eggs determined.

\section{Alcohol dehydrogenase activity assays}

Samples were taken of $F O_{F}, O_{F} F, S O_{S}$ and $O_{S} S$ eggs (F1 eggs) aged 2, 6, 10, 14, 18 or 22 hours; this was done for eggs derived from both regular food and food containing 4 per cent ethanol (the samples of 22 hours from regular food were composed of eggs and very young first instar larvae in a ratio of about $7: 3$ ). Immediately after sampling 100 eggs for each sample were frozen at $-25^{\circ} \mathrm{C}$. For measuring in vitro $\mathrm{ADH}$ activities the samples were homogenised in $0.1 \mathrm{ml} 0.05 \mathrm{M}$ Tris- $\mathrm{HCl}$ $0 \cdot 001 \mathrm{M}$ EDTA buffer of $p \mathrm{H} 8 \cdot 5$. The homogenates were centrifuged $\left(5 \mathrm{~min}, 5000 \mathrm{rpm}, 0^{\circ} \mathrm{C}\right)$ and $0.06 \mathrm{ml}$ of the supernatant was added to $0.84 \mathrm{ml}$ homogenization buffer and $0.1 \mathrm{ml}$ of a solution consisting of $1 \mathrm{M}$ isopropanol and $0.01 \mathrm{M} \mathrm{NAD}^{+}$. The initial increase in absorbance at $334 \mathrm{~nm}$ in the reaction mixture was measured in a spectrofotometer (light path $1 \mathrm{~cm}, 25^{\circ} \mathrm{C}$ ). For each genotype and age three replicates were measured; enzyme activities were expressed as $\Delta E . \mathrm{min}^{-1}$. $100 \mathrm{eggs}^{-1}$.

\section{Phenotypic adaptation on media supplemented with different alcohols}

To investigate on which alcohols phenotypic adaptation is exhibited, egg-to-adult survival of 


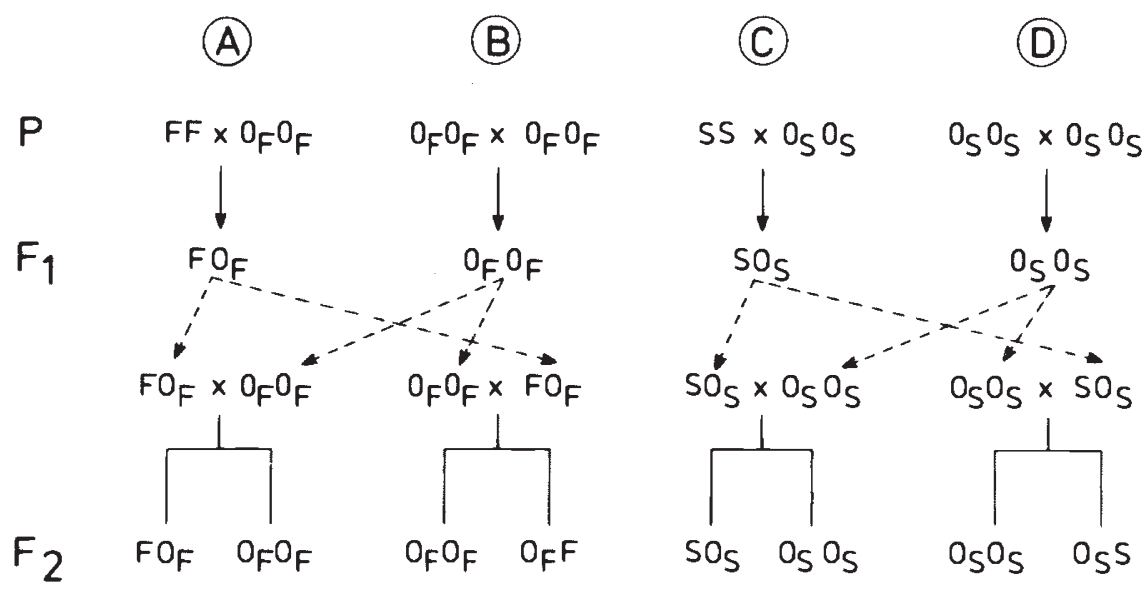

Figure 2 Crossing scheme used to investigate the influence of the maternal genotype on egg-to-adult survival. $F F$ and $S S$ strains are the strains from regular food ( $F N$ and $S N$ respectively).

$F N, S N, F E$ and $S E$ was determined on regular food and on food supplemented with one of several alcohols (table 1). The alcohol concentrations used in case of the $E$ strains were, except for ethanol, higher than those used in case of the $N$ strains as in another experiment (not published) the strains selected on ethanol food appeared to have developed cross resistance to several other alcohols.

Stimulation of egg production and collection of eggs were performed as described before. The flies used were all raised under identical uncrowded conditions on regular food during one generation preceding the experiment.

For all strains and ages 5 replicates of 50 eggs were transferred to vials with $9 \mathrm{ml}$ of regular food and to vials containing food with one of the alcohols mentioned in table 1 . The number of emerging flies in each vial was determined.

\section{RESULTS}

\section{Induction of tolerance during the egg stage}

Table 2 shows that it is clear that untreated eggs on regular food showed the highest viability; irrespective of the age at transfer to fresh regular food egg-to-adult survival was about 70 per cent for all strains. For eggs transferred to 12 per cent ethanol food the results were quite different; those transferred at an early age ( 2 or 8 hours) produced significantly more adults than eggs which were transferred later (14 or 18 hour-old eggs). There were no differences in survival in experiment $\mathbf{A}$ between $F N, F E$ and $S E$ on ethanol food if the eggs were transferred to this medium at an early
Table 1 Concentrations of the alcohols (per cent $v / v$ ) used to investigate the occurrence of phenotypic adaptation

\begin{tabular}{lcc}
\hline Alcohol & $N$ strains & $E$ strains \\
\hline Methanol $(M)$ & 3.00 & $3 \cdot 50$ \\
Ethanol $(E)$ & $15 \cdot 00$ & $15 \cdot 00$ \\
Propanol $(P)$ & $2 \cdot 75$ & 3.00 \\
Isopropanol $(I P)$ & $2 \cdot 75$ & $3 \cdot 00$ \\
Butanol $(B)$ & $2 \cdot 50$ & $2 \cdot 75$ \\
Hexanol $(H)$ & 0.50 & 0.65 \\
Octanol $(O)$ & 0.085 & $0 \cdot 10$ \\
Glycerol $(G)$ & 15.00 & $18 \cdot 00$ \\
\hline
\end{tabular}

age. The viability of the eggs of all three strains exceeded that of $S N$ eggs in this case. If, however, the eggs were transferred to ethanol food later, the viability of the $E$ strains was significantly higher than the viability of both $N$ strains. Furthermore egg-to-adult survival of $F N$ and $F E$ was considerably higher compared with $S N$ and $S E$ respectively.

After treatment with an ethanol solution (12 per cent $v / v$ ) for either 0.5 or 2.0 hours during the egg stage (pulse induction, experiment B) the viability of the eggs on regular food decreased as compared with the viability of untreated eggs. This decrease was greatest in $S N$ eggs: about 32 per cent, the percentual decrease in viability of $F N$, $F E$ and $S E$ eggs was almost equal: 15,13 and 12 per cent respectively (see table 2 ). The age of the eggs at the moment of pulse induction was unimportant with respect to the eventual percentages of emergence on regular food; in all cases the relative loss of viability of ethanol-treated eggs as compared with nontreated eggs of each strain was almost identical. 
The difference in the duration of the induction period did not result in differences in egg-to-adult survival on ethanol food; in all cases the survival of the eggs which had been exposed to the ethanol solution for 30 minutes was equal to the survival of the eggs exposed for 2 hours as can be seen in the bottom part of table 2 . Usually the eggs treated with the ethanol solution exhibited a survival equal to that of nontreated eggs (from experiment A) transferred to ethanol food at the end of the egg period (18 hour-old eggs). However, for eggs of the $E$ strains, which were exposed to ethanol for a short period as they were 2 hours old, the number of emerging adults was significantly lower compared with those of all other eggs from the same strains. The reason for this phenomenon is unclear at the moment, but it is known that, if females are forced to lay eggs very rapidly, the egg membranes may not be fully developed (Yoon and Fox, 1965). As a result it may be possible that some substances can penetrate through the membrane of young eggs while in older eggs this is no longer possible.

\section{Influence of maternal effects on egg-to-adult survival}

A control experiment (data not presented) showed that on regular food egg-to-adult survival of the parent strains was about 75 per cent. The differences in egg-to-adult survival of the reciprocal crosses
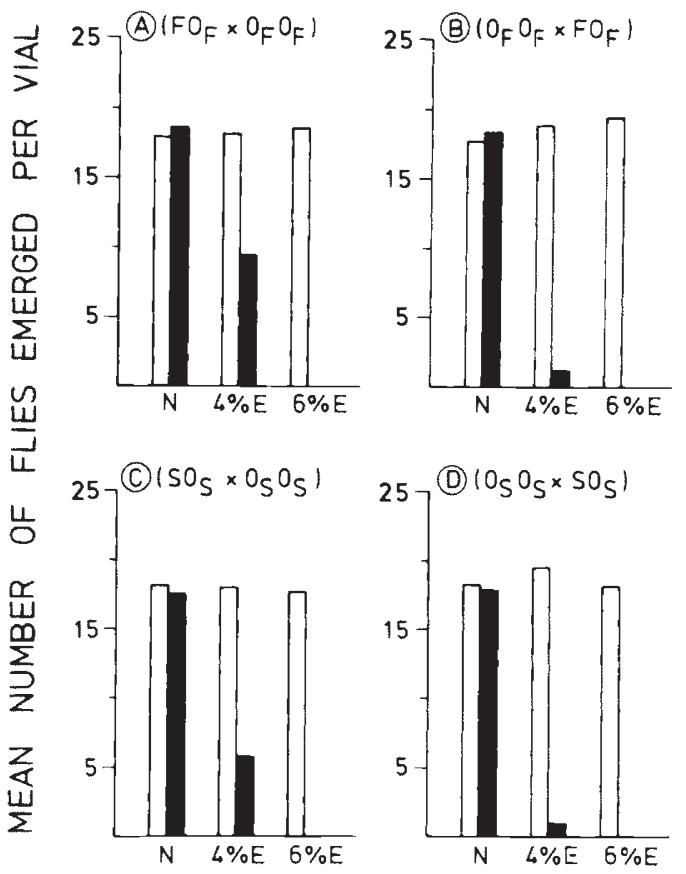

$=$ ADH - POSITIVE FLIES

$=A D H-N E G A T I V E$ FLIES

Figure 3 Egg-to-adult survival of the F2 of the reciprocal crosses between ADH positive and ADH negative flies in relation to ethanol concentration. The number of eggs in each vial was $50 . N=$ regular food; 4 , respectively 6 per cent $E=$ food supplemented with 4 , respectively 6 per cent ethanol by volume.

Table 2 Mean egg-to-adult survival (per cent) of the strains tested for induction of ethanol tolerance during the egg-stage. The number of replicates was five; the number of eggs per replicate 50 . The bottom part of the table shows the survival on ethanol food for each treatment in decreasing order; treatments not significantly different at the 5 per cent level (SNK-test) are underlined by a common line

\begin{tabular}{|c|c|c|c|c|c|c|c|c|c|}
\hline \multirow[b]{2}{*}{ Experiment } & \multirow[b]{2}{*}{ Treatment* } & \multicolumn{2}{|c|}{$F N$} & \multicolumn{2}{|c|}{$S N$} & \multicolumn{2}{|c|}{$F E$} & \multicolumn{2}{|c|}{$S E$} \\
\hline & & $N \dagger$ & $E \dagger$ & $N$ & $E$ & $N$ & $E$ & $N$ & $E$ \\
\hline \multirow[t]{3}{*}{ A } & I & $72 \cdot 3$ & $61 \cdot 4$ & $70 \cdot 2$ & $34 \cdot 6$ & $70 \cdot 6$ & $62 \cdot 3$ & $68 \cdot 1$ & $61 \cdot 6$ \\
\hline & III & N.M. & $8 \cdot 3$ & N.M. & $0 \cdot 7$ & N.M. & $43 \cdot 5$ & N.M. & $30 \cdot 7$ \\
\hline & IV & $73 \cdot 6$ & $6 \cdot 3$ & $71 \cdot 7$ & $0 \cdot 3$ & $70 \cdot 8$ & $39 \cdot 2$ & $70 \cdot 0$ & $28 \cdot 7$ \\
\hline \multirow{4}{*}{ B } & VII & N.M. & $8 \cdot 7$ & N.M. & $4 \cdot 3$ & N.M. & $42 \cdot 7$ & N.M. & $25 \cdot 6$ \\
\hline & VIII & $60 \cdot 4$ & $11 \cdot 4$ & $50 \cdot 9$ & $2 \cdot 7$ & $58 \cdot 4$ & $41 \cdot 4$ & $60 \cdot 3$ & $28 \cdot 8$ \\
\hline & IX & N.M. & $6 \cdot 4$ & N.M. & $1 \cdot 0$ & N.M. & $43 \cdot 4$ & N.M. & $30 \cdot 8$ \\
\hline & $X$ & $58 \cdot 0$ & $5 \cdot 8$ & $46 \cdot 1$ & 0.7 & $64 \cdot 7$ & $41 \cdot 0$ & $61 \cdot 5$ & $26 \cdot 1$ \\
\hline
\end{tabular}

* Treatments are denoted in fig. 1.

$\dagger N=$ regular food, $E=$ ethanol food $(12$ per cent $\mathrm{v} / \mathrm{v})$.

$\ddagger$ N.M. $=$ not measured.

$\begin{array}{lrllllllllllll}F N & \text { II } & \text { I } & \text { VIII } & \text { VII } & \text { III } & \text { IX } & \text { IV } & \text { X } & \text { V } & \text { VI } \\ S N & \text { I } & \text { II } & & \text { VII } & \text { VIII } & \text { IX } & \text { X } & \text { III } & \text { V } & \text { IV } & \text { VI } \\ F E & \text { II } & \text { I } & & \text { III } & \text { IX } & \text { VII } & \text { VIII } & \text { X } & \text { IV } & \text { VI } & \text { V } \\ S E & \text { I } & \text { II } & & \text { IX } & \text { III } & \text { VIII } & \text { IV } & \text { X } & \text { VII } & \text { VI } & \text { V }\end{array}$


between $F N$ and $O_{F}$ or $S N$ and $O_{S}$ were negligible. In all cases between 75 and 80 per cent of the eggs produced adults, which was in agreement with the survival of the homozygous $\mathrm{ADH}$ positive genotypes. A similar survival was found for $F N$ and $S N$ on 4 per cent ethanol; in that case, however, the viability of $O_{F}$ and $O_{S}$ was almost zero. The results of the egg-to-adult survival of the F2-crosses involving flies heterozygous and flies homozygous for the $A d h^{n 1}$ allele are given in fig. 3. On regular food $\mathrm{ADH}$ positive and negative flies exhibited identical viabilities; all genotypes showed survival percentages of 70-75 which was in agreement with the survival of the parent strains in the control experiment.

The same was observed for the egg-to-adult survival of the ADH positive flies on ethanol supplemented food; in this respect no differences were found between the reciprocal crosses while furthermore the number of emerging $F O_{F}$ flies was identical to that of $S O_{S}$ flies. On 4 per cent ethanol food hardly any ADH negative flies emerged from the crosses that involved an $\mathrm{ADH}$ negative mother (b and d). For the reciprocal crosses, however, involving $\mathrm{ADH}$ positive mothers ( $\mathrm{a}$ and $\mathrm{c}$ ) a considerable number of Adh-null flies was found, though the number of surviving Adh-null flies in this case was significantly lower than the number of null flies emerging at regular food $(P<0.001)$. Furthermore it was found that the viability of null-eggs from $F O_{F}$ mothers was significantly higher $(P<0.05)$ than that of eggs from $S O_{F}$ mothers. On food supplemented with 6 per cent ethanol no $\mathrm{ADH}$ negative flies at all emerged.

\section{Alcohol dehydrogenase activity assays}

The in vitro $\mathrm{ADH}$ activities of embryos at several times during egg development are summarised in table 3.

Production of ADH by eggs started just prior to hatching. Embryos from ADH negative mothers showed, at least on regular food, no detectable ADH until the age of 18 hours; on ethanol food $\mathrm{ADH}$ activity was observed even later.

Eggs laid by $\mathrm{ADH}$ positive females exhibited considerable $\mathrm{ADH}$ activity over the entire egg stage; the in vitro $\mathrm{ADH}$ activity of $F O_{F}$ was significantly higher than that of $S O_{s}$.

During the first 10 hours of development no significant differences in $\mathrm{ADH}$ activity could be demonstrated between eggs from regular food and eggs from ethanol food. Thereafter the differences between the activities on both food media became significant $(P<0 \cdot 01)$. On ethanol food $\mathrm{ADH}$ activity was constant over the total egg period. On regular food, however, a substantial decrease in $\mathrm{ADH}$ activity was observed in the course of development; after 18 hours there was no further decrease in enzyme activity, probably because of the expression of the Adh locus of the eggs by that time.

\section{The occurrence of phenotypic adaptation on various alcohols}

To investigate, whether phenotypic adaptation could also be induced by alcohols other than ethanol, egg-to-adult survival of the $N$ and the $E$ strains was studied on regular food and on food

Table 3 In vitro ADH activities of $F_{1}$ embryos from reciprocal crosses between ADH positive and ADH negative strains at several ages. Activities are expressed as $\Delta E .10^{3} \cdot \mathrm{min}^{-1} .100 \mathrm{eggs}^{-1}$; standard errors are given in parentheses. The number of replicates for each cross and sample time was 3

\begin{tabular}{|c|c|c|c|c|c|c|c|c|}
\hline \multirow{3}{*}{$\begin{array}{l}\text { Mean age of } \\
\text { the eggs (h) }\end{array}$} & \multirow{2}{*}{\multicolumn{2}{|c|}{$F O_{F}{ }^{*}$}} & \multirow{2}{*}{\multicolumn{2}{|c|}{$O_{F} F^{*}$}} & \multicolumn{4}{|l|}{ Senotypes } \\
\hline & & & & & SO & & $O_{S} S \dagger$ & \\
\hline & $N \ddagger$ & $E \ddagger$ & $N$ & $E$ & $N$ & $E$ & $N$ & $E$ \\
\hline 2 & $29 \cdot 6(1 \cdot 2)$ & $28.6(1 \cdot 4)$ & 0 & 0 & $9 \cdot 0(0 \cdot 5)$ & $9 \cdot 6(0.5)$ & 0 & 0 \\
\hline 6 & $29 \cdot 4(2 \cdot 1)$ & $28 \cdot 3(1 \cdot 7)$ & 0 & 0 & $9 \cdot 5(0 \cdot 3)$ & $9 \cdot 2(0.4)$ & 0 & 0 \\
\hline 10 & $26 \cdot 1(0 \cdot 8)$ & $29 \cdot 2(2 \cdot 2)$ & 0 & 0 & $7 \cdot 9(0 \cdot 2)$ & $8.9(0.7)$ & 0 & 0 \\
\hline 14 & $19 \cdot 4(1 \cdot 1)$ & $28 \cdot 7(1 \cdot 1)$ & 0 & 0 & $6 \cdot 1(0 \cdot 3)$ & $9.3(0.9)$ & 0 & 0 \\
\hline 18 & $16 \cdot 2(0 \cdot 9)$ & $28 \cdot 1(1 \cdot 4)$ & $0 \cdot 7(0 \cdot 2)$ & 0 & $5 \cdot 0(0 \cdot 3)$ & $8 \cdot 8(1 \cdot 0)$ & $0 \cdot 1(0)$ & 0 \\
\hline $22 \|$ & $24 \cdot 5(2 \cdot 7)$ & $29 \cdot 9(1 \cdot 6)$ & $2 \cdot 9(0 \cdot 6)$ & $1.8(0.4)$ & $7.7(0.9)$ & $10 \cdot 1(0 \cdot 5)$ & $1 \cdot 7(0 \cdot 3)$ & $0 \cdot 8(0 \cdot 1)$ \\
\hline
\end{tabular}

* $F O_{F}=$ eggs from a cross between $F N \uparrow q$ and $O_{F} \delta \delta ; O_{F} F=$ eggs from the reciprocal cross.

$\dagger S O_{S}=$ eggs from a cross between $S N \& q$ and $O_{S}$ ठठ $\delta$; $O_{S} S=$ eggs from the reciprocal cross.

$\neq N=$ eggs laid on regular food; $E=$ eggs laid on food containing ethanol ( 4 per cent $\mathrm{v} / \mathrm{v}$ ).

$\|$ The samples from regular food were composed of eggs and very young first instar larvae in a ratio of about $7: 3$. 
supplemented with one of the following alcohols: methanol, ethanol, propanol, isopropanol, butanol, hexanol or glycerol. The $E$ strains were used to see whether the longterm adaptation to ethanol had influenced the capability for phenotypic adaptation. The results are shown in fig. 4(a-d).

It is clear that in the case of the $N$ strains phenotypic adaptation occurred on food supplemented with the primary alcohols ethanol, propanol, butanol and hexanol as shown by decreasing curves of egg-to-adult survival in fig. 4(a) and (b). Analyses of variance showed significant $(P<$ $0.01)$ effects of the age of transfer and interaction between this variable and food media for these alcohols. On food supplemented with methanol, isopropanol, octanol or glycerol phenotypic adaptation could not be demonstrated. It could be argued that for some alcohols the concentrations were too low to induce this phenotypic effect; it was calculated, however, that egg-to-adult survival on the alcohol containing media, with the exception of glycerol, was significantly lower than on regular food $(P<0.01)$. Thus apparently there is a toxic effect of these alcohols, which is not associated with phenotypic adaptation. With regard to the $E$ strains decreasing curves of egg-to-adult survival (fig. 4(c) and (d)) and significant $(P<$ 0.01 ) effects of age of transfer and interaction (analysis of variance) could only be demonstrated on ethanol food. As the survival on regular food always significantly $(P<0.001)$ exceeded survival on all alcohols these results appear to justify the conclusion that the $E$ strains, in contrast to the $N$ strains, only exhibited the phenotypic effect on ethanol supplemented food.
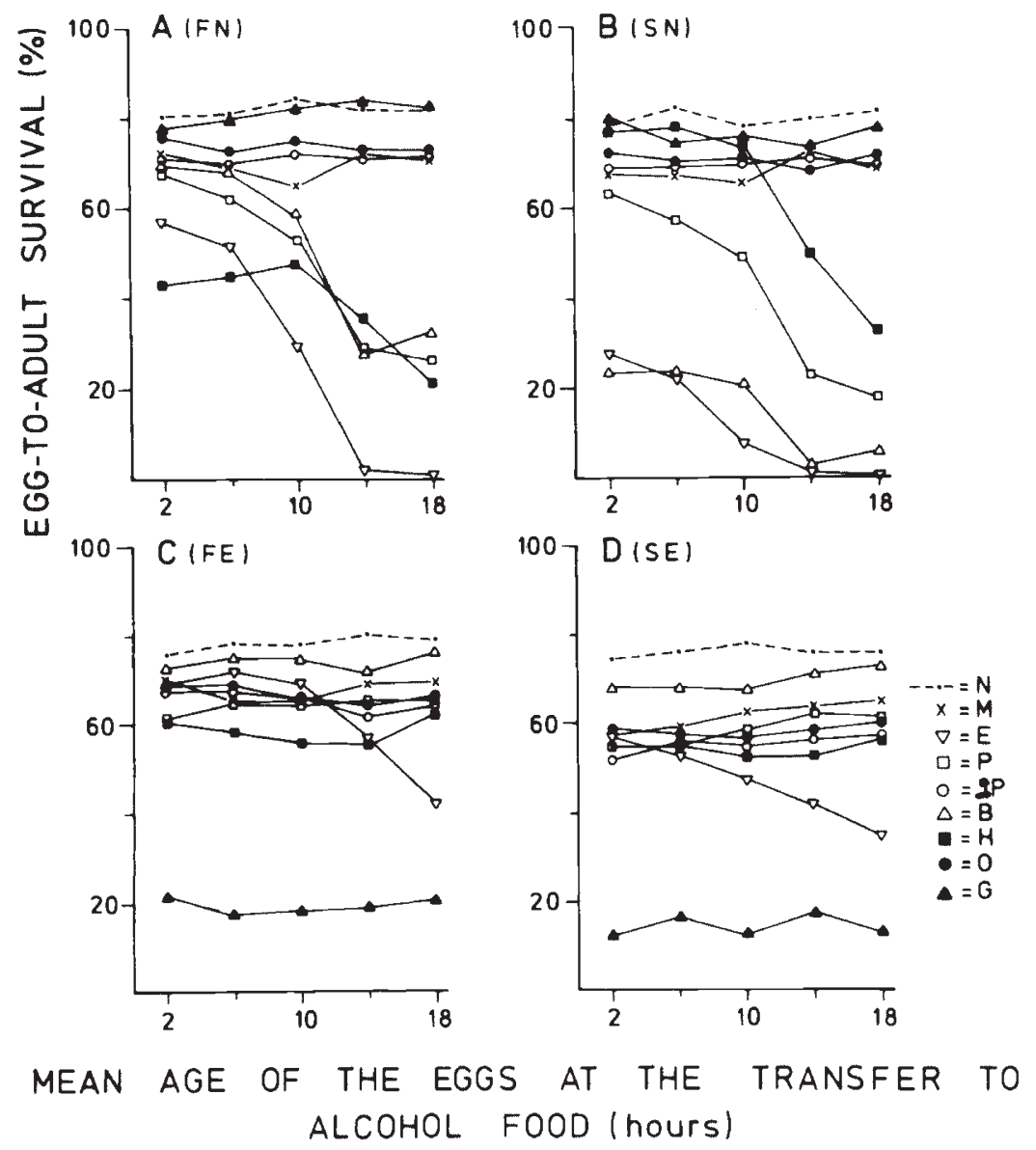

Figure 4 Egg-to-adult survival of control strains ( $F N$ and $S N$ ) and selected strains ( $F E$ and $S E$ ) after transfer to food supplemented with various alcohols in relation to the age of the eggs at the moment of transfer. $N=$ regular food (control). For the alcohols and concentrations used see table 1 . 
DISCUSSION

\section{Induction of tolerance}

Considerable differences in survival are found in the experiment on phenotypic induction of tolerance to ethanol in eggs. Eggs, transferred to fresh regular food without having been exposed to ethanol show 70 per cent survival, irrespective of age of transfer.

When eggs are transferred to ethanol supplemented food, however, the age of the eggs at the moment of transfer is of paramount importance: young eggs ( 2 or 8 hours old) exhibit a far higher survival than old ( 14 or 18 hours old), a phenotypic adaptation described earlier by Bijlsma-Meeles (1979). The significantly lower viability of $S N$ eggs on ethanol food compared with $F N$ eggs, correlated with a lower ADH activity of the former eggs, is also in agreement with her results. Although $F E$ and $S E$ eggs also differ considerably in $\mathrm{ADH}$ activity, the lower viability of $S E$ eggs compared with $F E$ eggs is shown at 14 and 18 hours only. The $E$ strains are, however, highly tolerant to ethanol (Kerver and Van Delden, 1985) and this may explain the lack of differences in survival for 2 and 8 hour-old eggs. Furthermore the large decrease in viability of the "late" $N$ eggs compared with "late" $E$ eggs also is probably the result of adaptation to ethanol of the $E$ strains.

Treatment of 0.5 or 2.0 hours with a 12 per cent ethanol solution at different moments during the egg stage does not result in improved egg-toadult survival on ethanol food. Both eggs from the $N$ and $E$ strains that were temporarily exposed to the ethanol solution and untreated eggs produced equal numbers of adults after transfer to ethanol food at an age of 18 hours. Young larvae, just after hatching, seem to be the most susceptible to the toxic effects of ethanol: all eggs transferred from regular food to ethanol food, irrespective of age at transfer, hatch but the larvae from eggs transferred after 12 hours die within a few hours (E. Bijlsma-Meeles, pers. comm.). Larvae from eggs transferred early during the egg stage appear to be better protected against the toxic ethanol effect than larvae from eggs transferred later (table 2). Our results suggest that phenotypic adaptation to ethanol occurs only if the eggs stay permanently on the ethanol medium from early in development. Phenotypic adaptation is not limited to ethanol food alone; at least for the $N$ strains it is also observed on food supplemented with either propanol, butanol or hexanol. In case of the $E$ strains it is only found on food containing ethanol, but the extend is far less than for the $N$ strains. The reasons for this are unknown.

\section{Maternal effect}

From the experiments with flies heterozygous for the $A d h^{n 1}$ allele it is clear that on regular food the viability of $\mathrm{ADH}$ negative eggs is identical to the viability of $\mathrm{ADH}$ positive eggs. On 4 per cent ethanol food, however, the survival of the ADH negative genotypes is significantly lower as compared with regular food. While considerable numbers of $\mathrm{ADH}$ negative flies emerge from crosses with $\mathrm{ADH}$ positive females, the surviving offspring of the reciprocal crosses consists almost entirely of flies with functional ADH (see fig. 3). The differential survival of $A d h$-null genotypes is probably caused by maternal effects. Early embryonic development is largely conditioned by the large amount of cytoplasm that contains the products of the maternal genes (Gerasimova and Smirnova, 1979).

$\mathrm{ADH}$ positive females can transfer $\mathrm{ADH}$ or mRNA for manufacturing ADH to the egg cytoplasm but $\mathrm{ADH}$ negative females are unable to do so. As the activity of $F F-A D H$ exceeds that of SS-ADH (Kerver and Van Delden, 1985) this explains the higher viability of genotypically $A d h^{n 1}$ eggs from $F F$ mothers compared with identical eggs from $S S$ mothers. On food containing 6 per cent ethanol no ADH negative flies at all are found; apparently this amount of ethanol is too high, so that the positive action of the maternal effect can no longer efface the negative effect of ethanol. The $F O_{F}$ and $S O_{S}$ genotypes possess maternal ADH during the egg stage but also synthesise their own $\mathrm{ADH}$ at hatching (Wright and Shaw, 1970; Leibenguth, Rammo and Dubiczky, 1979); therefore these genotypes show normal viabilities at the relatively low ethanol concentrations used in this experiment. The potential for heterozygotes to synthesize their own ADH seems to be enough to overcome the deleterious effects of 4 per cent and 6 per cent ethanol.

The differences between $O_{F} F$ and $O_{S} S$ eggs (from $\mathrm{ADH}$ negative mothers) on the one hand and $F O_{F}$ and $S O_{S}$ eggs (from $\mathrm{ADH}$ positive mothers) on the other can be explained by the maternal effect. This also explains the higher in vitro $\mathrm{ADH}$ activities of $F O_{F}$ eggs compared with $S O_{S}$ eggs as it seems likely that females will transfer equal amounts of maternal products to the egg cytoplasm. Our determination of ADH activities at six different intervals shows that there is no detectable de novo production of $\mathrm{ADH}$ in the egg 
stage until hatching (table 3: $O_{F} F$ and $O_{S} S$ eggs). Indeed, there is if anything a decrease on regular food while ADH activity seems to be constant on ethanol supplemented food (table 3: $F O_{F}$ and $S O_{S}$ eggs). The finding that late eggs from ethanol food possess higher ADH levels compared with late eggs from regular food may possibly be explained by the formation of an alcohol dehydrogenaseethanol-complex in the former eggs. It is known that such an enzyme-substrate-complex is generally more stable than the free enzyme (Katanuma, Kito and Kominami, 1971 $a, b$ ); NAD and $\mathrm{NADH}$ also will stabilise the enzyme molecule. Such a phenomenon may also explain the constancy of ADH activity on ethanol food and the decrease in activity on regular food. Another possible explanation for the constant level of in vitro $\mathrm{ADH}$ activity on ethanol food may be that the rate of degradation of maternal $\mathrm{ADH}$ is eclipsed by the rate of synthesis of new ADH by translation of the maternal mRNA; in this case constancy would be due to mRNA. A comparable situation is reported by Gerasimova and Smirnova (1979) who showed that in the case of 6 phosphogluconate dehydrogenase (6PGD) long-lived stable mRNA was transmitted with the egg cytoplasm and translated during the development of D. melanogaster, leading to large increase of 6PGD activity even in the absence of a functional $\mathrm{Pgd}$ gene. However, in the case of ADH this would imply that the rate of synthesis from the maternal mRNA is exactly the same as the rate of degradation of the maternal $\mathrm{ADH}$. Therefore it seems more likely that the constancy of the ADH activity in this case is due to a stabilising effect of ethanol treatment.

\section{Relation between phenotypic adaptation and maternal effect}

It is possible that phenotypic adaptation is in some way related to the maternal effect. Eggs transferred from regular food to ethanol food at an early age may maintain the level of maternal ADH throughout the egg stage because of the formation of an $\mathrm{ADH}$-ethanol-complex enabling a higher larval tolerance to etnanol. It is not yet known if phenotypic adaptation can also occur in the absence of ADH; perhaps it will only be observed when there is stabilisation of maternal $\mathrm{ADH}$ by ethanol (or other primary alcohols). It is clear, however, that the absolute level of $\mathrm{ADH}$ is not the sole determinant of the phenotypically induced tolerance because phenotypically adapted $S S$ genotypes have a much better survival than non- adapted $F F$ genotypes (table 2), while their in vitro $\mathrm{ADH}$ activity is significantly lower than that of the latter genotypes (Bijlsma-Meeles, 1979; Van Delden, 1984; Kerver and Van Delden, 1985).

The processes described in this paper may explain why strains selected for ethanol tolerance in the adult life stage (David and Bocquet, 1977; McDonald et al., 1977) show a significantly larger increase in $L_{50}$ in adults compared to strains which are exposed to ethanol continuously (Kerver and Van Delden, 1985). In the former strains maternal effects and phenotypic adaptation do not play a role in the selection procedure, while they are always present in the latter strains.

As both phenomena are highly beneficial in case of exposure to ethanol, the response to selection in juvenile stages will be far less than in case of selection in the adult life stage only. The finding of a higher tolerance to ethanol in populations from a winecellar compared with noncellar populations without differentiation in allele frequencies (McKenzie and Parsons, 1974; McKenzie and McKechnie, 1978) may also be related to phenotypic adaptation (and perhaps maternal effects) in cellar populations. In general it appears that phenotypic adaptation and maternal effects have great influence on the survival of Drosophila melanogaster on alcohol food, although phenotypic adaptation is not seen after short term exposure of eggs to ethanol. Its mechanism is not fully elucidated yet; maternal effect is probably caused by maternal $\mathrm{ADH}$, stored in the egg cytoplasm during oogenesis. The importance of $\mathrm{ADH}$ in the survival of $D$. melanogaster on alcohol is clear, but $\mathrm{ADH}$ activity alone does not predict the survival of flies in these circumstances.

Acknowledgements We thank W. van Delden and R. Bijlsma for helpful discussion. Thanks are due to Ms S. Walburgh Schmidt for typing the manuscript and to $\mathrm{H}$. Mulder for preparing the figures.

This investigation was supported by the Foundation for Fundamental Biological Research (BION) which is subsidized by the Netherlands Organization for the Advancement of Pure Research (Z.W.O.).

\section{REFERENCES}

BIJLSMA-MEELES, E. 1979. Viability in Drosophila melanogaster in relation to age and $\mathrm{ADH}$ activity of eggs transferred to ethanol food. Heredity, 42, 79-89.

BRISCOE, D. A., ROBERTSON, A. AND MALPICA, M. J. 1975. Dominance at the $A d h$ locus in response of adult Drosophila melanogaster to environmental alcohol. Nature, $255,148-149$. 
CAStelli, T. 1954. Les agents de la fermentation vinaire. Arch. Microbiol, 20, 323-342.

DAVID, J. R. AND BOCQUET, C. 1977. Genetic tolerance to ethanol in Drosophila melanogaster: Increase by selection and analysis of correlated responses. Genetica, 47, 43-48.

GERASIMOVA, T. I. AND SMIR NOVA, S. G. 1979. Maternal effect for genes encoding 6-phosphogluconate dehydrogenase and glucose-6-phosphate dehydrogenase in Drosophila melanogaster. Developm. Genet., 1, 97-107.

GIBSON, J. 1970. Enzyme flexibility in Drosophila melanogaster. Nature, 227, 959-960.

GRELL, E. H., JACOBSON, K. AND MURPHY, J. B. 1968. Alterations of genetic material for analysis of alcohol dehydrogenase isozymes of Drosophila melanogaster. Ann N.Y. Acad. Sci., 151, 441-455.

HORIKAWA, M., KING, L. N. L. AND FOX, A. S. 1967. Effects of substrates on gene-controlled enzyme activities in cultured embryonic cells of Drosophila. Genetics, 55, 569-583.

HULME, A. C. 1970. The Biochemistry of Fruits and their Products, Volume 1, Academic Press, New York.

HUlME, A. C. 1971. The Biochemistry of Fruits and their Products, Volume 2, Academic Press, New York.

KATANUMA, N., KOMINAMI, E. AND KOMINAMI, S. 1971 a. A new enzyme that specifically inactivates apo-protein of pyridoxal enzymes. Biochem. Biophys. Res. Commun., 45, $70-75$.

KATANUMA, N., KITO, K. AND KOMINAMI, E. 1971b. A new protein that specifically inactivates apo-protein of NADdependent dehydrogenases. Biochem. Biophys. Res. Commun., 45, 76-81.

KERVER, J. W. M. AND VAN DELDEN, w. 1985. Development of tolerance to ethanol in relation to the alcohol dehydrogenase locus in Drosophila melanogaster. I. Adult and egg-to-adult survival in relation to $\mathrm{ADH}$ activity. Heredity, $55,355-367$.

LEIBENGUTH, F., RAMMO, E. AND DUBICZKY, R. 1979. A comparative study of embryonic gene expression in
Drosophila and Ephestia. Wilhelm Roux' Arch. Dev. Biol., 187, 81-88.

MCDONALD, J. F., CHAMBERS, G. K., DAVID, J. AND AYALA, F. J. 1977. Adaptive response due to changes in gene regulation: A study with Drosophila. Proc. Natl. Acad. Sci. USA, $74,4562-4566$.

MCKENZIE, J. A. AND MCKECHNIE, S. W. 1978. Ethanol tolerance and the $A d h$ polymorphism in a natural population of Drosophila melanogaster. Nature, 272, 75-76.

MCKENZIE, J. A. AND MCKECHNIE, S. W. 1979. A comparative study of resource utilization in natural populations of Drosophila melanogaster and Drosophila simulans. Oecologia, 10, 373-388.

MCKENZIE, J. A. AND PARSONS, P. A. 1974. Microdifferentiation in a natural population of Drosophila melanogaster to alcohol in the environment. Genetics, 77, 385-394.

SOKAL, R. R. AND ROHLF, F. J. 1981. Biometry, W. H. Freeman and Company, San Francisco, pp. 239-246.

VAN DELDEN, w. 1982. The alcohol dehydrogenase polymorphism in Drosophila melanogaster. Selection at an enzyme locus. Evol. Biol., 15, 187-222.

VAN DELDEN, w. 1984. The alcohol dehydrogenase polymorphism in Drosophila melanogaster, facts and problems. In K. Wöhrmann and V. Loeschcke (eds.) Population Biology and Evolution. Springer Verlag, Berlin, pp. 127-142.

VAN DELDEN, W., BOEREMA, A. C. AND KAMPING, A. 1978. The alcohol dehydrogenase polymorphism in populations of Drosophila melanogaster. I. Selection in different environments. Genetics, 90, 161-191.

VAN DELDEN, W. AND KAMPING, A. 1981. Selection against an Adh null allele. Dros. Inf. Serv., 56, 149-150.

WRIGHT, D. A. AND SHAW, C. R. 1970. Time of expression of genes controlling specific enzymes in Drosophila embryos. Biochem. Genet., 4, 385-394.

YOON, S. B. AND FOX, A. S. 1965. Permeability of premature eggs from Drosophila collected with the "Ovitron". Nature, 206, 910-913. 